\title{
Innovative Strategies for Building Community Among Faculty Who Teach in Virtual Environments
}

\author{
Sara L. Schwartz \\ Eugenia L. Weiss \\ June L. Wiley
}

\begin{abstract}
A previous qualitative study (Schwartz, Wiley, \& Kaplan, 2016) described the faculty experiences and reflections of delivering Master of Social Work (MSW) education via a virtual platform at the University of Southern California, Suzanne Dworak-Peck School of Social Work during its initial years of operation. Thematic analysis revealed a need for community building amongst geographically diverse faculty. Given social work's emphasis on the person-in-environment perspective, it is imperative to consider the experiences of those individuals responsible for executing virtual technology-supported programs and delivering education via virtual platforms. The current paper describes innovative institutional and programmatic interventions implemented to promote community and collaboration among faculty who teach virtually. Creating strategic opportunities for virtual and ground-based faculty to connect informally and formally has the potential to foster a culture of inclusivity, connection, and a productive community of practice.
\end{abstract}

Keywords: Virtual teaching; dispersed faculty; community of practice

The use of Internet technology in the delivery of social work education is a rapidly evolving phenomenon. Although the profession of social work has used technology to access individuals and train them to serve hard-to-reach communities for many years, over the past decade we have witnessed unprecedented growth in the application of technology to social work education. As of 2016, over $80 \%$ of accredited Bachelor of Social Work (BSW) and Master of Social Work (MSW) programs around the United States now offer some form of hybrid or online programming (Robbins, Coe Regan, Williams, Smyth, \& Bogo, 2016). Additionally, the American Academy of Social Work and Social Welfare (AASW) has identified one the profession's Grand Challenges to include the use of technology in ameliorating societal ills, through the challenge of "harness[ing] technology for the social good" (Uehara et al., 2015, p. 3). Examining the ways that technology can be effectively applied to the education and training of social workers is an important area of inquiry given the demands for online programming in higher education and the global need for training qualified practitioners.

A robust literature examines the experiences of students enrolled in online programs and their educational outcomes. Research has focused on the many advantages of online education, particularly with regards to increasing access to individuals with disabilities and those living in hard-to-reach communities (Bryant, Garnham, Tedmanson, \& Diamandi, 2015; Reamer, 2013; Stolzer, 2012; Tandy \& Meacham, 2009). Overall student satisfaction

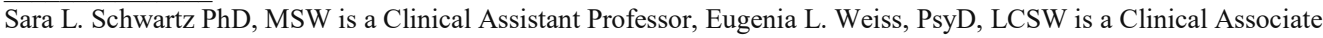
Professor and Senior Associate Dean of Faculty Affairs, and June L. Wiley, PhD, MSW is a Clinical Associate Professor and Assistant Dean, Virtual Academic Center, at the Suzanne Dworak-Peck School of Social Work, The University of Southern California, Los Angeles, CA 90015. 
and learning outcomes are consistent across education delivery types, (i.e., traditional onthe-ground and online; Ayala, 2009; Cappiccie \& Desrosiers, 2011; Constantine Brown \& Park, 2016; Cummings, Chaffin, \& Cockerham, 2015; Hill Jones, 2015; Wretman \& Macy, 2016; York, 2008). Challenges associated with online education include difficulties with virtual communication with classmates, inexperience with virtual learning tools, and lack of perceived student-instructor connection (Noble \& Russell, 2013; Secret, Bentley, \& Kadolph, 2016). However, a systematic review of papers published prior to 2013 finds students are largely satisfied with virtual education experiences (Wretman \& Macy, 2016).

There is far less known about the experiences of instructors in virtual education as compared to what we know about online students or faculty teaching in traditional classroom settings (Nicklin, McNall, Cerasoli, Varga, \& McGivney, 2016). Here we define virtual education as comprising synchronous live classroom discussions where students and faculty interact at the same time and virtually face-to-face through Adobe Connect technology (as opposed to online programs comprised of only asynchronous course work). Recent and emerging literature informs us that virtual faculty are largely satisfied with their instruction, particularly appreciating the flexibility, work-life balance, and student diversity in the virtual classroom (Huang \& Hsiao, 2012; Peach \& Bieber, 2015; Schwartz, Wiley, \& Kaplan, 2016). Challenges identified by virtual faculty include technology comfort level, availability of support and training, and feelings of alienation from peers and the larger organization (Curry, 2016; Dolan, 2011; Levin, Whitsett, \& Wood, 2013; Lloyd, Byrne, \& McCoy, 2012; Milton, Sinclair, \& Vakalahi, 2016; Smith, 2015). Given social work's emphasis on the person-in-environment perspective, it is imperative to consider the experiences of those individuals responsible for executing virtual technologysupported programs and delivering education via virtual platforms.

Drawing a parallel to organizational workplaces beyond institutions of education, one of the most pressing challenges facing managers of dispersed virtual workspaces is building an environment that promotes trust, connection, and a sense of belonging among distributed employees (Milton et al., 2016; Wenger, McDermott, \& Snyder, 2002). A defining feature of working in virtual teams is that communication primarily occurs through the use of virtual tools as modes of communication, which can influence outcomes and experiences in a number of ways related to frequency of interaction, quantity of information shared, timeliness of communication, and engagement with colleagues (Marlow, Lacerenza, \& Sales, 2017; Sardeshmukh, Sharma, \& Golden, 2012). Research on communication and satisfaction of virtual teams is conflicting, with some studies finding that workers are more satisfied with low levels of communication with colleagues and others are less so (Akkirman \& Harris, 2005; Cooper \& Kurland, 2002).

\section{Previous Findings on Virtual Education}

In an effort to examine faculty experiences and reflections on delivering MSW education via the University of Southern California Suzanne Dworak-Peck School of Social Work, Virtual Academic Center (VAC) during its first four years of operation, an exploratory cross-sectional study was launched in 2014 (see Schwartz et al., 2016). Nonprobability quota and purposive sampling strategies were used and semi-structured telephone interviews were conducted with 25 faculty members. The interview questions 
included: "From your experience, what are the opportunities and challenges of being an instructor on the VAC?" and "How do you experience community in the VAC?" The sample represented faculty from tenure line $(\mathrm{n}=5 ; 20 \%)$, and non-tenure Clinical Teaching $(\mathrm{n}=7 ; 28 \%)$, non-tenure Clinical Field $(\mathrm{n}=1 ; 4 \%)$ and adjunct part-time faculty $(\mathrm{n}=12$; $48 \%$ ). Data collection and interview selection adhered to traditional grounded theory techniques (Charmaz, 2014; Glasser \& Strauss, 1967). Data were uploaded into NVivo 10 software for data management and thematic analysis.

The inductive qualitative analysis resulted in the identification of three overarching themes. The first theme focused on building a geographically diverse academic community, the second on community building among faculty, and the third on community building among faculty and students. Interviews from this previous study suggested that virtual faculty felt dissatisfied with their opportunities to communicate with colleagues about work processes in a meaningful way. This is reflected in the following quote by a Caucasian, male 50-year old full-time Clinical Field Faculty member (non-tenure track):

You also don't really have casual interactions with the other professors. Sometimes like on the ground you'll be talking and realize oh we're both having this issue with this student. It wasn't a groundbreaking huge thing but casually talking you realize oh we are having this common experience, or with this group of students or whatever it might be. Again, you have to be very intentional about having those meetings but you don't have those sort of casual things where you learn about things as a group and that connection is harder.

A quote from another virtual instructor, a female, a full-time Clinical Teaching Faculty (non-tenure track) in her seventies addresses the lack of satisfaction with communication and community building:

I think starting in January, maybe this past year, [the program director], widely began to have meetings of the full-time [faculty], I guess the lead VAC faculty meetings, but those meetings have not really generated the kind of interaction, or at least the kind that I need, with my peers. They've been more structured and more informational, top down informational kinds of things....

As the VAC has grown in enrollment from its first cohort of 88 students to a current enrollment of approximately 2,000 students, hiring additional faculty has been critical to respond to the growing demand. These hires ensure that all students regardless of academic center enrollment (on-the-ground versus virtual) have instructors who bring exceptional academic and real-world experiences to their classroom, thereby creating an optimal learning environment. The current paper focuses on how the school of social work has addressed the theme of community building gleaned from the Schwartz et al. (2016) study and emerging research on the needs of geographically dispersed virtual instructors.

\section{Innovative Strategies for Community Building}

Wenger et al.'s (2002) Community of Practice Model considers the vital roles played by organizational communities in facilitating knowledge management, learning innovation, and outcome achievement. This model, in conjunction with other literature on 
building community in virtual environments, provides a framework from which the school launched several strategies to address the needs of VAC faculty with limited opportunities for face-to-face interaction with their supervisors and peers.

Wenger et al. (2002) offer insight into building effective communities of practice in geographically distributed communities, asserting that these communities can be developed and nurtured by attending to four key development areas. First, it is important to achieve stakeholder alignment, which in large organizations is most effectively achieved by developing smaller sub-communities that facilitate small group connection, local variation, and connection to the larger community of practice. Second, the organization must create structures that promote connections among people within and across subcommunities. Third, it is important to recognize that distributed community members do not naturally bump into each other, thus it is necessary to create opportunities for all participants to maintain visibility through teleconferences, newsletters, email threads, and face-to-face meetings that rotate locations. Finally, organizations need to incorporate networking opportunities to create a web of trust across the larger community using strategies that can include small group projects, meetings, displaying the faces and bios of distributed workers on the organization's webpage, and organizing in-person small group visits (Wenger et al., 2002). These recommendations echo suggestions by other authors acknowledging the necessity of creating pathways for virtual employees to informally and formally communicate with each other in order to build trust, develop community, create opportunities for employee development, operationalize best practices, and achieve organizational outcomes (Adedoyin, 2016; Akkirman \& Harris, 2005; Cooper \& Kurland, 2002; Milton et al., 2016).

To promote faculty development across program location and career track and to provide greater opportunities for engagement, collaboration, and community building, USC's VAC launched five innovative strategies that were rolled out incrementally 20122016: 1) Semi-annual Virtual Academic Center Faculty Retreats, 2) Monthly Hybrid Faculty Meetings, 3) The Virtual Water Cooler, 4) Wellness Activities, and 5) The Virtual Book Club.

\section{Semi-Annual Virtual Academic Center Faculty Retreats}

The USC Suzanne Dworak-Peck School of Social Work began sponsoring semi-annual Virtual Academic Center Faculty Retreats in 2012. These meetings are mandatory and all expenses are paid for full-time virtual faculty. For part-time adjunct faculty, attendance is recommended, but not required (or funded). The meetings are held twice a year - once during the fall semester and once during the spring semester. The retreats assemble fulltime VAC faculty, who also serve as lead instructors for part-time faculty, to address issues pertinent to the school and the virtual program. The fall retreat occurs during the annual Council of Social Work Education Annual Program Meeting held in different regions of the country, which permits faculty to convene at a location that may be closer to their residence. The spring retreat requires faculty to assemble on the university campus, typically around the time of graduation ceremonies in order to encourage virtual faculty to attend these celebrations. These retreats reflect Wenger et al.'s (2002) suggestion that inperson meetings be hosted in alternating locations. 
Consistent with the idea of strengthening the sense of community, the day-long retreat agendas incorporate topics that are identified as meaningful to faculty along with topics established by the administration to respond to policy and related academic matters. Examples of recent topics include: diversity and inclusion in the classroom; building mentorship relationships among faculty; curriculum revisions; and student competency evaluations. Program agendas are created to allow for ample socialization time during breaks, meals, and activities provided by the school's Wellness Committee, whose purpose is to promote healthy living and to provide tools for faculty to engage in and practice selfcare.

\section{Hybrid Faculty Meetings}

While the Faculty Retreats respond to the geographic distance that exists among the full-time VAC faculty with limited opportunities to engage with one another in the same locale, other community building efforts have also been established. At the time of the Schwartz et al. study (2016), virtual instructors logged into faculty meetings to observe the proceedings but had few options to interact with their colleagues in the meeting. In order to conduct the most effective faculty meetings that capitalize on all faculty resources, the school began to explore ways to ensure that all faculty members, regardless of rank or geography, are able to fully participate in faculty meetings and that their involvement be recognized and valued. To facilitate this change, a protocol was unanimously approved by the faculty and administration and put into place to host hybrid meetings which required school funding to build technologically equipped meeting rooms. Fiscal budgeting to build out technology capacity was instrumental for hybrid meetings and is in line with the larger university strategic plan to enhance technology.

These updated meeting rooms have the capacity to display the faces of virtual faculty logged into the meeting on large screens and enable remote faculty to participate in real time via the chat box or audio system. A new procedure for hosting hybrid faculty meetings was distributed to all faculty and these changes coincided with a restructuring of the MSW program into three separate departments (e.g., Children, Youth and Families; Social Innovation and Change; Adult Mental Health and Wellness). Both the new hybrid meeting protocols and departmentalization appear to have facilitated faculty connections and are in line with the Wenger et al. (2002) recommendation for creating smaller sub-communities or hubs that relate to the larger, more complex organizational community as well as creating ways for virtual faculty faces to become recognizable.

\section{Virtual Water Cooler}

Some of the strategies used to build community among virtual faculty have evolved from the faculty as bottom-up interventions. For instance, beginning in 2016, three VAC faculty launched the Virtual Water Cooler whereby faculty recreate the water cooler experience (i.e., times for informal gatherings and sharing). Unlike the faculty meetings and retreats that are convened to address academic and policy matters of the school, these virtual "water cooler" sessions are primarily for the faculty to chat and virtually meet faceto-face about topics of interest to them and to become acquainted with one another. These water cooler sessions echo Wenger's et al. (2002) "communities of practice" in that this 
need to meet and share information has arisen from the faculty (not created by administration) based on their shared experience of being virtual faculty and wanting to engage in topics of mutual interest (p.130). The water coolers are typically held three times a semester and do not have specific agendas. However, sometimes the water coolers organically concentrate on a particular topic such as opportunities for advancement within the school, classroom management strategies, and current events (e.g., elections, natural disasters, etc.).

\section{Wellness Activities}

Another activity designed to foster community building has been the creation of the school's Wellness Committee, as previously mentioned. The committee's focus on healthy living encourages the participation of all faculty — on-ground and virtual. What makes the group's work attractive for the virtual faculty is that the design of the activities permit participation regardless of where faculty are physically located. For example, the Wellness Committee has sponsored virtual bus tours, learning about various regions of the country and the world via the use of the electronic platform, negating the need for faculty to be physically present. When these activities are designed to foster physical activity, they are coordinated so the members can join a local physical activity group, providing feedback and photos to the rest of the faculty of what occurred. These activities, such as virtual yoga sessions or Smoothie challenges, create opportunistic chances to support, interact, and engage with colleagues that can help build what Wenger et al. (2002) refer to as a "web of trust."

\section{Virtual Book Club}

Finally, as another step in enhancing the faculty's sense of community, a subcommittee of the Wellness Committee, the Virtual Book Club, began in the fall of 2016. The Wellness Virtual Book Club explores diversity through fiction. Book club members select a book for the month and convene to discuss the book on the virtual platform, with member's rotating facilitation duties each meeting. The book club was intended to engage faculty in a shared experience and stimulating discussions with other faculty who can bring diversity of geographic location and individual expertise to the forum. A small group of about a dozen faculty consistently attended the book club in 2016 and 2017, reading and discussing eleven books.

\section{Conclusion}

Over the past decade, the profession of social work has leveraged technology in such a way that the field has undergone considerable shifts in the education and training of social workers as well as the ways that services may be delivered to clients (e.g., tele-mental health). In fact, one of the profession's stated Grand Challenges for the next decade is to establish new ways to use technology to foster social good (Uehara et al., 2015). While internet technology creates unique opportunities to engage with hard-to-reach populations and to train a geographically diverse workforce around the country, it remains important to consider one of the basic tenets of the profession - to view the person in his/her environment. 
As the profession continues to advance its use of technology and more virtual education programs are launched, it is imperative to examine how this new paradigm shift is experienced by the people who spend considerable time working in virtual spaces. Schwartz et al.'s (2016) findings that virtual instructors often feel disconnected from the larger university culture and alienated from geographically distant colleagues is reflected in other published work examining online education. Dolan (2011) and Curry (2016) found that online adjunct faculty often feel disconnected from the larger organization, that they are not presented opportunities to get to know and trust their colleagues and that they are often not recognized as valuable resources for the organization. Cooper and Kurland (2002) find that professional alienation is inversely linked with virtual employee professional development, suggesting that telecommuters have limited opportunities for informal learning, interpersonal networking, and mentoring which directly impacts employee development. Smith (2015) echoes a concern for lack of formal mentoring opportunities available to virtual faculty in USC's Virtual Academic Center, particularly for those faculty who hold part-time adjunct positions in the school. These findings are relevant to the Schwartz et al. (2016) study given that almost half of the respondents identified as adjunct faculty.

The challenges identified above are reflected in Wenger's et al. (2002) seminal work on cultivating communities of practice and Adedoyin's (2016) examination of virtual communities of practice. The authors consider geographically distributed communities that cannot rely on face-to-face meetings, asserting that this distance creates unique challenges for creating and being a part of an organizational community. As a response to both the Schwartz et al. (2016) study and a growing literature considering the community building needs of online faculty, USC launched the five strategies to facilitate formal and informal opportunities for faculty across rank and campus location that are presented in this paper.

\section{Implications for Future Research and Practice}

There is anecdotal evidence that these five strategies are fruitful in building connections among dispersed faculty at this particular school of social work by generating new opportunities to get to know one another, which is one of the first steps of building a successful community of practice. The new hybrid meeting technology has created ways for virtual and ground faculty to begin to visually recognize each other, which has translated to informal gatherings at professional meetings. Twice-a-year in-person meetings for full-time virtual faculty provide opportunities for both informal and formal interaction, which has cultivated a sense of community amongst a geographically dispersed faculty and increased the engagement of virtual faculty in hybrid meetings. New collaborations have been established through these relationships, which is evidenced by new partnerships on conference presentations, curricular design, and peer mentorship groups.

These new collaborative efforts and anecdotal evidence of increased engagement suggest that the tactics employed by the USC Suzanne Dworak-Peck School of Social Work to engage virtual faculty and build community are working. This has implications for other schools launching online social work programs with a geographically dispersed faculty body. These strategies may also be useful for ground-based faculty in large 
institutions who may have few opportunities to build connections, collaborate with peers, and develop efficient communities of practice despite a shared physical campus.

In order to more comprehensively assess the effectiveness of these community building strategies, a mixed-methods evaluation is under development. Evaluation of these interventions will entail the use of an online survey of virtual faculty with regards to their perceived sense of community in relation to the aforementioned initiatives. In-depth faculty feedback will also be attained through interviews. Through the evaluation we seek to learn what activities the faculty are participating in and whether or not these initiatives are helpful in their perceptions of community building. We also hope to glean information about the potential barriers for participation. This information may be useful to develop and implement additional interventions to improve faculty members' sense of community in the virtual teaching environment which can, in turn, enhance job satisfaction and performance in the classroom.

\section{References}

Adedoyin, A. C. A. (2016). Deploying virtual communities of practice as a digital tool in social work: A rapid review and critique of the literature. Social Work Education, 25(3), 357-370. doi: https://doi.org/10.1080/02615479.2016.1154660

Akkirman, A. D., \& Harris, D. L. (2005). Organizational communication satisfaction in the virtual workplace. Journal of Management Development, 24(5), 397-409. doi: https://doi.org/10.1108/02621710510598427

Ayala, J. S. (2009). Blended learning as a new approach to social work education. Journal of Social Work Education, 45(2), 277-288. doi: https://doi.org/10.5175/JSWE.2009.200700112

Bryant, L., Garnham, B., Tedmanson, D., \& Diamandi, S. (2015). Tele-social work and mental health in rural and remote communities in Australia. International Social Work, 61(1), 143-155. doi: https://doi.org/10.1177/0020872815606794

Cappiccie, A., \& Desrosiers, P. (2011). Lessons learned from using Adobe Connect in the social work classroom. Journal of Technology in Human Services, 29, 296-302. doi: https://doi.org/10.1080/15228835.2011.638239

Charmaz, K. (2014). Constructing grounded theory ( $2^{\text {nd }}$ ed). Thousand Oaks, CA: Sage.

Constantine Brown, J. L., \& Park, H-S. (2016). Longitudinal student research competency: Comparing online and traditional face-to-face learning platforms. Advances in Social Work, 17(1), 44-58. doi: https://doi.org/10.18060/20870

Cooper, C. D., \& Kurland, N. B. (2002). Telecommuting, professional isolation, and employee development in public and private organizations. Journal of Organizational Behavior, 23, 511-532. doi: https://doi.org/10.1002/job.145

Cummings, S. M., Chaffin, K. M., \& Cockerham, C. (2015). Comparative analysis of an online and traditional MSW program: Educational outcomes. Journal of Social Work Education, 51(1), 109-120. doi: https://doi.org/10.1080/10437797.2015.977170 
Curry, S. P. (2016). Effects of the virtual environment on online faculty perceptions of leadership: A grounded theory study (Doctoral Dissertation Northcentral University). Available from ProQuest Dissertations and Thesis database. (ProQuest 10110291)

Dolan, V. (2011). The isolation of online adjunct faculty and its impact on their performance. International Review of Research in Open and Distance Learning, 12(2), 62-77. doi: https://doi.org/10.19173/irrodl.v12i2.793

Glaser, B. G., \& Strauss, A. L. (1967). The discovery of grounded theory. New York: Adline.

Hill Jones, S. (2015). Benefits and challenges of online education for clinical social work: Three examples. Clinical Social Work Journal, 43, 225-235. doi: https://doi.org/10.1007/s10615-014-0508-z

Huang, X. S., \& Hsaio, E-L. (2012). Synchronous and asynchronous communication in an online environment: Faculty experiences and perceptions. The Quarterly Review of Distance Education, 13(1), 15-30.

Levin, S., Whitsett, D., \& Wood, G. (2013). Teaching MSW social work practice in a blended online learning environment. Journal of Teaching in Social Work, 33(4-5), 408-420. doi: https://doi.org/10.1080/08841233.2013.829168

Lloyd, S, A., Byrne, M. M., \& McCoy, T. S. (2012). Faculty-perceived barriers of online education. MERLOT Journal of Online Learning and Teaching, 8(1), 1-12.

Marlow, S. L, Lacerenza, C. N., \& Salas, E. (2017). Communication in virtual teams: A conceptual framework and research agenda. Human Resource Management Review, 27(4), 575-589. doi: https://doi.org/10.1016/j.hrmr.2016.12.005

Milton, S. A., Sinclair, M. M., \& Vakalahi, H. O. (2016). Organizational identification: Perspectives of dispersed social workers. Advances in Social Work, 17(2), 285-303. doi: https://doi.org/10.18060/21014

Nicklin, J. M., McNall, L. A., Cerasoli, C. P., Varga, C. M., \& McGivney, R. J. (2016). Teaching online: Applying need theory to the work-family interface. The American Journal of Distance Education, 30(3), 167-179. doi: https://doi.org/10.1080/08923647.2016.1187042

Noble, D., \& Russell, A. C. (2013). Research on webbed connectivity in a web-based learning environment: Online social work education. Journal of Teaching in Social Work, 33(4-5), 496-513. doi: https://doi.org/10.1080/08841233.2013.829167

Peach, H. G., \& Bieber, J. P. (2015). Faculty and online education as a mechanism of power. Distance Education, 36(1), 26-40. doi: https://doi.org/10.1080/01587919.2015.1019971

Reamer, F. (2013). Distance and online social work education: Novel ethical challenges. Journal of Teaching in Social Work, 33(4-5), 369-384. doi: https://doi.org/10.1080/08841233.2013.828669 
Robbins, S. P., Coe Regan, J. R., Williams, J. H., Smyth, N. J., \& Bogo, M. (2016). From the Editor - The future of social work education. Journal of Social Work Education, 52(4), 387-397. doi: https://doi.org/10.1080/10437797.2016.1218222

Sardeshmukh, S. R., Sharma, D., \& Golden, T. D. (2012). Impact of telework on exhaustion and job engagement: A job demands and job resources model. New Technology, Work and Employment, 27(3), 193-207. doi: https://doi.org/10.1111/j.1468-005X.2012.00284.X

Schwartz, S. L., Wiley, J. L., \& Kaplan, C. D. (2016). Community building in a virtual teaching environment. Advances in Social Work, 7(1), 15-30. doi: https://doi.org/10.18060/20875

Secret, M., Bentley, K. J., \& Kadolph, J. C. (2016). Student voices speak quality assurance: Continual improvement in online social work education. Journal of Social Work Education, 52(1), 30-42. doi: https://doi.org/10.1080/10437797.2016.1112630

Smith, W. (2015). Relational dimensions of virtual social work education: Mentoring faculty in a web-based learning environment. Clinical Social Work Journal, 43, 236245. doi: https://doi.org/10.1007/s10615-014-0510-5

Stolzer, R. L. (2012). Serving rural communities with distance education degree programs. Journal of Technology in Human Services, 30(2), 109-117. doi: https://doi.org/10.1080/15228835.2012.699510

Tandy, C., \& Meacham, M. (2009). Removing the barriers for students with disabilities: Accessible online and web-enhanced courses. Journal of Teaching in Social Work, 29(3), 313-328. doi: https://doi.org/10.1080/08841230903022118

Uehara, E. S., Barth, R. P., Olson, S., Catalano, R. F., Hawkins, J. D., Kemp, S., Nurius, P. S.,...Sherraden, M. (2015). Identifying and tackling grand challenges for social work (Grand Challenges for Social Work Initiative Working Paper No. 3). Baltimore, MD: American Academy of Social Work and Social Welfare. Retrieved from http://aaswsw.org/wp-content/uploads/2015/12/WP3-with-cover.pdf

Wenger, E., McDermott, R., \& Snyder, W. (2002). Cultivating communities of practice: A guide to managing knowledge. Boston: Harvard Business School.

Wretman, C. J., \& Macy, R. J. (2016). Technology in social work education: A systematic review. Journal of Social Work Education, 52(4), 409-421. doi: https://doi.org/10.1080/10437797.2016.1198293

York, R. O. (2008). Comparing three modes of instruction in a graduate social work program. Journal of Social Work Education, 44(2), 157-172. doi: https://doi.org/10.5175/JSWE.2008.200700031

Author note: Sara L. Schwartz, PhD, MSW, Suzanne Dworak-Peck School of Social Work, The University of Southern California, 1150 S. Olive Street, Suite T-1100, Los Angeles, CA 90015. saraschw@usc.edu 